\section{Alles über die Haut mit einem Griff}

P odopompholyx - was ist das noch einmal? Akne - welche klinischen Formen gibt es? Psoriasis vulgaris welche Therapieoptionen bestehen? Antimykotische Salbe - wie wird die korrekt rezeptiert? Ob es um Dermatologie, Allergologie oder Umweltmedizin geht: Ein einziger Griff genügt, um zur gesuchten Information zu gelangen. Der neue „Altmeyer, Paech“ bietet in bewährter Form präzise und gut strukturiert alles Wissenswerte zu Klinik, Diagnostik und Therapie.

In der zweiten Auflage wurden die Inhalte wie auch die Abbildungen um- fassend aktualisiert. Über 5.000 Stichwörter auf 2.100 Seiten behandeln alle Facetten der Dermatologie, Allergologie und Umweltmedizin. Wo erforderlich, visualisieren Tabellen kompakte Informationen und machen sie transparenter. Anschaulich und instruktiv illustriert werden die Inhalte durch 1.476 ausgewählte Abbildungen. Außerdem findet der Leser im aktualisierten Rezepturverzeichnis über 298 Magistralrezepturen auf dem aktuellen Stand der pharmazeutisch-technologischen Wissenschaft. Ganz neu dazugekommen ist ein separates Syno- nymenverzeichnis, das gebräuchliche und historische Begriffe wie Anglizismen gleichermaßen berücksichtigt und einen bequemen und sicheren Weg durch das dermatologische Sprachgewirr weist.

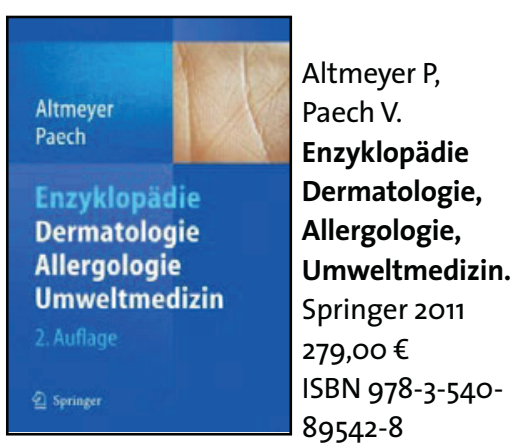

\title{
Richtig reden mit „schwierigen“ Patienten
}

\begin{abstract}
chon heute werden bis zu einem Fünftel der Patienten einer Praxis vom behandelnden Arzt als „schwierig“ eingestuft. Nicht wegen ihres komplizierten Krankheitsbilds, sondern wegen ihrer Art. Was tun: Resignieren? Zurechtweisen? Oder den Patienten verstehen und neue Zugangswege zu ihm finden?

Oft sind die Patienten nicht per se schwierig, sondern werden es nur durch mangelnde Achtsamkeit und schlechtes Zeitmanagement. Aber auch die kranke Seele hat Konjunktur. Kommunikation
\end{abstract}

mit Patienten ist daher das wichtigste Instrument in einer Praxis oder Klinik. Das Buch Gesprächs-Art kann Ärzte ebenso wie ihr Team dabei unterstützen. Die Autoren, Joachim Sandner und Volker Faust, vermitteln die Grundlagen guter Kommunikation speziell ausgerichtet auf den Patientenkontakt und stellen relevante Störungsbilder aus dem seelischen und psychosozialen Bereich umfassend dar. Wer sich mit diesen Grundlagen vertraut macht und dabei sein Gegenüber besser einschätzen kann, trägt wesentlich dazu bei, eine Gesprächssituation positiv zu beeinflussen und wird in Konfliktsituationen eine Reihe von Lösungswegen kennen und anwenden können. red

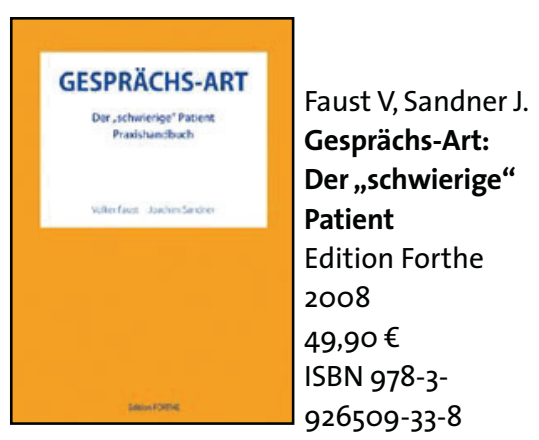

zwei Antikörpern auf der Mastzelloberfläche Grundbedingung ist.

Später baute de Weck das Institut für Allergologie und klinische Immunologie an der Universität Bern auf und initiierte verschiedene Projekte zum bes-

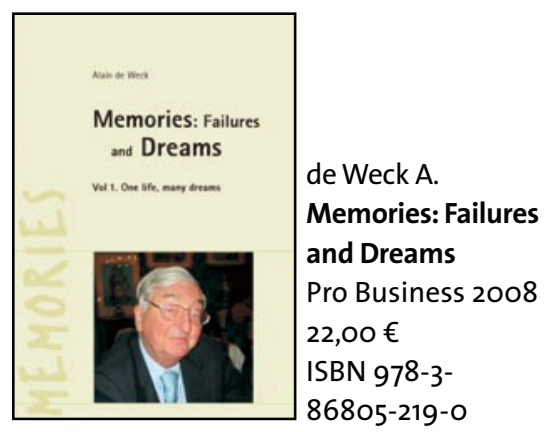

